\title{
Assessment of vasoconstrictive capacity of tall fescue alkaloids using fescue naïve lateral saphenous veins of crossbred heifer cattle
}

\author{
J.L. KLOTZ ${ }^{1}$, B.H. KIRCH ${ }^{1}$, G.E. AIKEN ${ }^{1}$, L.P. BUSH ${ }^{2}$, B.C. ARRINGTON ${ }^{2}$, and J.R. STRICKLAND ${ }^{1}$ \\ ${ }^{1}$ USDA-ARS, Forage-Animal Production Research Unit, Lexington, KY, USA \\ ${ }^{2}$ Department of Plant and Soil Sciences, University of Kentucky, Lexington, USA \\ jstrickland@ars.usda.gov
}

\begin{abstract}
Vasoconstriction is one response associated with consumption of toxic endophyte-infected tall fescue. Because it is not known if endophyte-produced alkaloids act alone or collectively, the objective of this study was to examine the vasoconstrictive potentials of D-lysergic acid, ergovaline, and $\mathrm{N}$-acetylloline individually or in paired combinations using bovine lateral saphenous veins biopsied from fescue naïve cattle. Segments (2$3 \mathrm{~cm}$ ) of vein were surgically biopsied from healthy Brahmaninfluenced yearling cattle $(\mathrm{n}=22 ; 330 \pm 8 \mathrm{~kg})$. The data indicated that ergovaline is a more potent vascular toxicant than lysergic acid and $\mathrm{N}$-acetylloline. Further, the presence of $\mathrm{N}$-acetylloline did not inhibit or potentiate the effects of the ergot alkaloids on vascular activity. The contractile responses of the remaining combinations
\end{abstract}

did appear to differ from the individual concentration responses. This supports the possibility that a combinatorial or repetitive alkaloid exposure effect may exist in vivo and should be considered during in vitro evaluations of ergot alkaloids.

Keywords: fescue-naïve cattle, fescue toxicosis, vasoconstriction

\section{Introduction}

In vitro screening of different alkaloids for vasoconstrictive effects has been done using a bovine lateral saphenous vein bioassay. Preliminary work in our lab has utilised tissue obtained from slaughtered animals. While obtaining tissue samples at abattoirs is less complicated, the dietary background of these animals in many cases is unknown and could be a source of

Figure 1 Mean contractile responses ( \pm standard error) of tall fescue-naïve bovine saphenous veins to $A$ ) increasing concentrations of ergovaline $(n=5)$; B) increasing concentrations of ergovaline in combination with $1 \times 10-5 \mathrm{M} \mathrm{N}$-acetylloline (NAL; $n=5) ; C$ ) increasing concentrations of ergovaline in combination with $1 \times 10^{-5}$ M lysergic acid (LSA; $\left.n=5\right)$; and D) increasing concentrations of $\mathrm{N}$-acetylloline in combination with $1 \times 10^{-7} \mathrm{M}$ ergovaline (ERV; $\left.n=5\right)$.
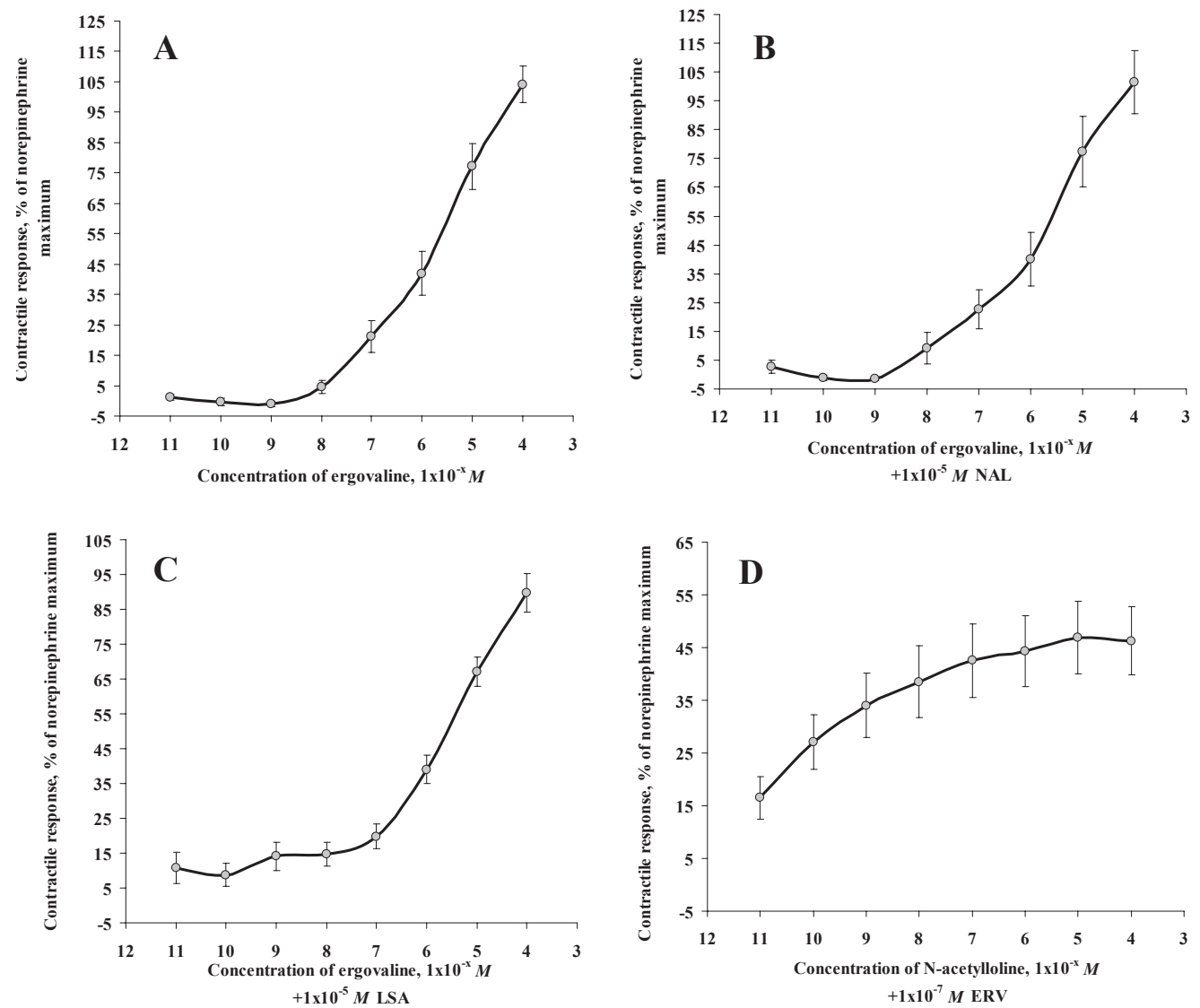
variation. Consequently, this experiment evaluated concentration responses of selected alkaloids using saphenous veins biopsied from fescue-naïve cattle.

The second component of the experiment was to evaluate alkaloids in combination. Because herbivores are exposed to a multiplicity of alkaloids when consuming toxic endophyteinfected tall fescue, a combined alkaloid effect has been suggested (Oliver 1997). However, there is presently no documented evidence of vasoconstrictive synergism of tall fescue alkaloids on the animal. Thus, the objective of this experiment was to examine the vasoconstrictive potentials of D-lysergic acid and ergovaline individually and in combination with either one another or Nacetylloline using lateral saphenous veins biopsied from fescuenaïve cattle.

\section{Methods}

Methods used in this study have been validated and reported in full by Klotz et al. (2006) and Solomons et al. (1989) and were approved by the University of Kentucky's Institutional Animal Care and Use Committee. To complete all of the reported treatment combinations, cranial branches of lateral saphenous veins were biopsied from 22 fescue naïve Angus x Brangus crossbred heifers (obtained from the USDA-ARS, Dale
Bumpers Small Farms Research Center, Booneville, AR; 330 $\pm 8 \mathrm{~kg}$ ). Animals were placed in a left lateral recumbency using a tilt table (Spring-O-Matic, Inc., Marion, KS) and the biopsy site was cleaned, disinfected, and localised with lidocaine. Biopsied venous tissue was placed in a modified-Krebs Henseleit oxygenated buffer solution $\left(95 \% \mathrm{O}_{2} / 5 \% \mathrm{CO}_{2} ; \mathrm{pH}=7.4\right)$ and kept on ice until processed.

Tissue processing consisted of removal of excess fat and connective tissue from the vein segments, which were then sliced into 2 to $3-\mathrm{mm}$ cross-sections. Duplicate cross-sections from each animal per treatment were suspended horizontally in a 5-mL tissue bath (DMT610M Multi-chamber myograph, Danish Myo Technologies, Atlanta, GA) containing continuously oxygenated modified-Krebs Henseleit buffer $\left(95 \% \mathrm{O}_{2} / 5 \% \mathrm{CO}_{2}\right.$; $\left.\mathrm{pH}=7.4 ; 37^{\circ} \mathrm{C}\right)$. This buffer also contained $3 \times 10^{-5} \mathrm{M}$ desipramine and $1 \times 10^{-6} \mathrm{M}$ propranolol to inactivate catecholamine-neuronal uptake and beta-adrenergic receptors, respectively. Following equilibration to $1 \mathrm{~g}$ of tension $(1.5 \mathrm{~h})$, tissues were exposed to an alpha-adrenergic agonist (norepinephrine, $1 \times 10^{-4} \mathrm{M}$ ) to verify tissue viability and to be used as reference for normalisation. Following the re-establishment of the 1 -g baseline tension $(\sim 45$ to $60 \mathrm{~min}$ ), additions of standards occurred in 15-min intervals. Increasing doses of ergovaline, lysergic acid, and $\mathrm{N}$-acetylloline

Figure 2 Mean contractile responses ( \pm standard error) of tall fescue-naïve bovine saphenous veins to A) increasing concentrations of lysergic acid $(n=5)$; B) increasing concentrations of lysergic acid in combination with $1 \times 10^{-5} M N^{-}$ acetylloline (NAL; $n=5$ ); C) increasing concentrations of lysergic acid in combination with $1 \times 10^{-7} M$ ergovaline (ERV; $n=5$ ); and $\mathrm{D}$ ) increasing concentrations of $\mathrm{N}$-acetylloline in combination with $1 \times 10^{-5} \mathrm{M}$ lysergic acid (LSA; $\left.n=5\right)$.
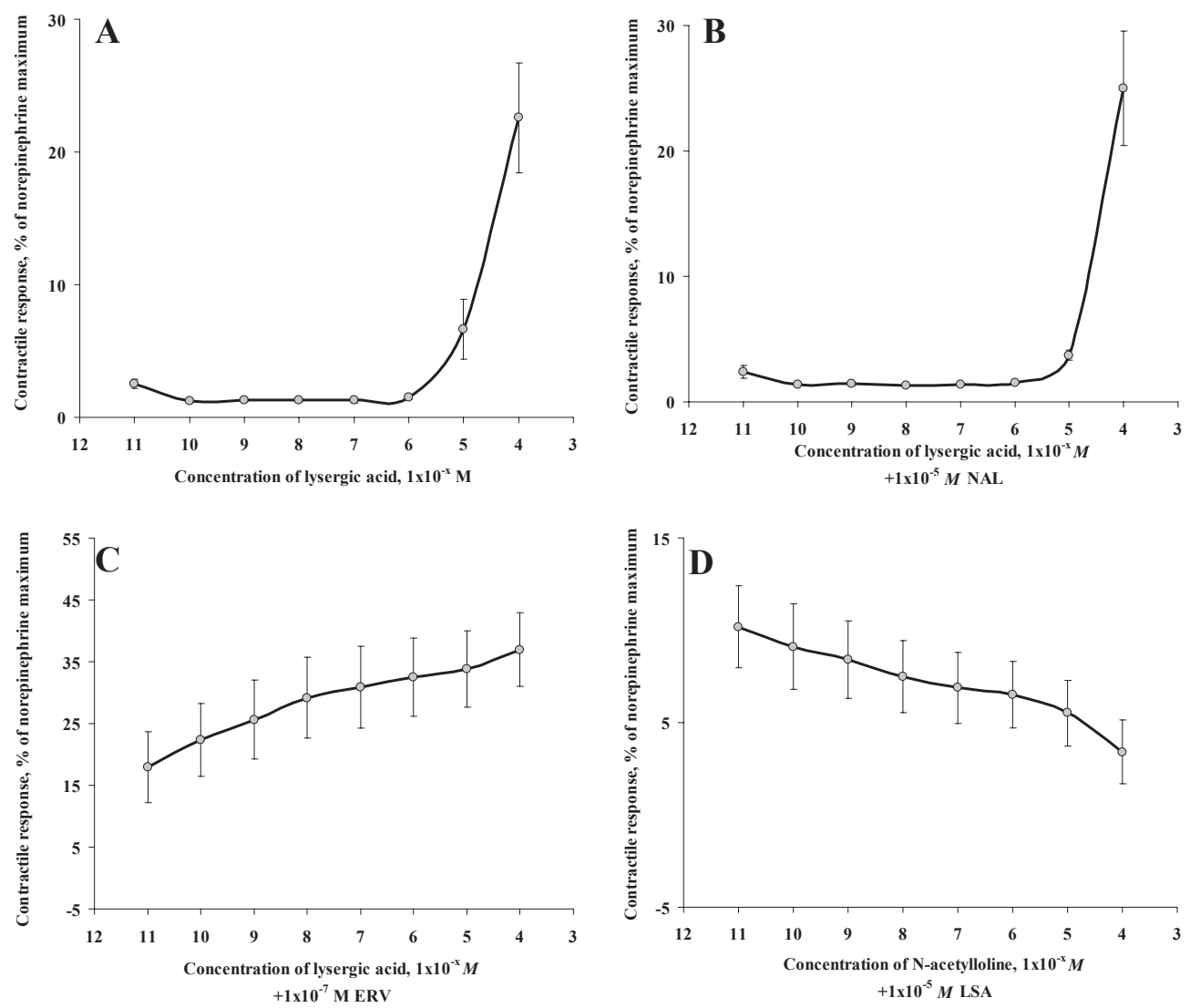
$\left(1 \times 10^{-11}\right.$ to $\left.1 \times 10^{-4} \mathrm{M}\right)$ individually or in combination (when in combination, lysergic acid and $\mathrm{N}$-acetylloline were held constant at $1 \times 10^{-5} \mathrm{M}$ and ergovaline at $1 \times 10^{-7} \mathrm{M}$ ) were administered every 15 min following buffer replacement.

Isometric contraction was recorded as grams of tension in response to exposure to norepinephrine and the subsequent alkaloid additions. Data were digitised and recorded using a Powerlab/8sp and Chart software (Version 5.3; ADInstruments, Colorado Springs, CO). All maximal values measured were corrected by the baseline measured during the interval preceding addition of norepinephrine generating a cumulative concentration response. To compensate for variation of tissue responsiveness due to differences in tissue size or individual animal variation, values were normalised as a percentage of the maximal contraction produced by norepinephrine. The data are presented as percent means of the maximal contraction induced by norepinephrine.

\section{Results and Discussion}

The contractile responses of tall fescue-naïve bovine lateral saphenous veins to increasing concentrations of ergovaline (Fig. 1A) and lysergic acid (Fig. 2A) were similar to those previously reported using tissues obtained from slaughtered animals (Klotz et al. 2006; unpublished data). Maximal contractile responses in the current study were $104.1 \%$ and $22.6 \%$, for ergovaline and lysergic acid, respectively. The addition of $1 \times 10^{-5} \mathrm{M} \mathrm{N}$ acetylloline did not seem to affect the contractile response to ergovaline (Fig. 1B; maximal contraction $=101.5 \%$ of norepinephrine), but the addition of $1 \times 10^{-5} \mathrm{M}$ lysergic acid may have slightly reduced the contractile intensity (Fig. 1C; maximal contraction $89.7 \%$ of norepinephrine). These data suggest that at higher levels of ergovaline $\left(1 \times 10^{-5}\right.$ and $\left.1 \times 10^{-4} \mathrm{M}\right)$, lysergic acid may function as an antagonist. In contrast, the addition of $1 \times 10^{-}$ ${ }^{5} \mathrm{M}$ lysergic acid caused the response curve to shift up at the $1 \times 10^{-11} \mathrm{M}$ concentration of ergovaline. This may be explained by the approximately $5 \%$ contractile response to $1 \times 10^{-5} \mathrm{M}$ lysergic acid when added alone, plus potentially a small additive effect of ergovaline. The cause of the contractile response in Fig. 1D is most likely due to increasing additions of $1 \times 10^{-7} \mathrm{M}$ ergovaline and not increasing concentrations of $\mathrm{N}$-acetylloline (when added solely, increasing concentrations of $\mathrm{N}$-acetylloline generated negligible contractile responses - data not shown).

When increasing concentrations of lysergic acid were combined with $1 \times 10^{-5} \mathrm{M} \mathrm{N}$-acetylloline (Fig. 2B; maximal contraction was $25.0 \%$ of the norepinephrine induced maximum), there was little change observed from the addition of lysergic acid alone. Like Fig. 1D with increasing concentrations of $\mathrm{N}$-acetylloline combined with $1 \times 10^{-7} \mathrm{M}$ ergovaline (Fig. 2C), the initial contractile response up to $1 \times 10^{-5} \mathrm{M}$ concentration of lysergic acid containing $1 \times 10^{-7} \mathrm{M}$ ergovaline most likely reflects cumulative effects of ergovaline exposure. The contractile response to $1 \times 10^{-}$ ${ }^{5}$ and $1 \times 10^{-4} \mathrm{M}$ concentrations of lysergic acid in the presence of $1 \times 10^{-7} \mathrm{M}$ concentration of ergovaline likely reflect additive affects of both alkaloids. The combination of $1 \times 10^{-5} \mathrm{M}$ lysergic acid with increasing concentrations of $\mathrm{N}$-acetylloline (Fig. 2D) generated an interesting contractile response. The tissue actually appeared to relax as the concentration of $\mathrm{N}$-acetylloline increased $\left(1 \times 10^{-11} \mathrm{M} \mathrm{N}\right.$-acetylloline $=10.2 \%$ and $1 \times 10^{-4} \mathrm{M} \mathrm{N}$-acetylloline $=3.4 \%$ of norepinephrine max). The initial contraction that was observed appeared to approximate the addition of $1 \times 10^{-5} \mathrm{M}$ lysergic acid (see Fig. 2A; 6.7\% of norepinephrine max), but then declined to approximately $3.4 \%$. Currently it is not clear as to why the tissue may have relaxed rather than maintaining a more constant tension that would have been predicted by the $1 \times 10^{-5} \mathrm{M}$ lysergic acid alone response.

Ergovaline and lysergic acid potencies (i.e. level at which contraction is initially detected) of $1 \times 10^{-8}$ and $1 \times 10^{-5} \mathrm{M}$ respectively, resembled those seen using tissue obtained from slaughtered animals (Klotz et al. 2006; unpublished data). The contractile intensities did appear slightly greater and are currently under investigation. There did appear to be some interaction of the alkaloids when the tissue was exposed to various combinations, however, it is difficult to discern the actual cause of the observed effect. It appears that $\mathrm{N}$-acetylloline did not inhibit or potentiate the effects of the ergot alkaloids on vascular activity to any appreciable extent. However, the remaining combinations did appear to differ from individual concentration responses. This lends credence to the possibility that synergistic or additive effects may exist in vivo and should be considered when using in vitro bioassays.

\section{ACKNOWLEDGEMENTS}

The authors wish to thank T. Hamilton, J. Jones, L. McClanahan, J. Piel, and B. Hightshoe for their assistance in helping to complete the biopsies.

\section{REFERENCES}

Klotz, J.L.; Bush, L.P.; Smith, D.L.; Shafer, W.D.; Smith, L.L.; Vevoda, A.C.; Craig, A.M.; Arrington, B.C.; Strickland, J.R. 2006. Assessment of vasoconstrictive potential of D-lysergic acid using an isolated bovine lateral saphenous vein bioassay. Journal of Animal Science 84: 3167-3175.

Oliver, J.W. 1997. Physiological manifestations of endophyte toxicosis in ruminant and laboratory species. pp. 311346. In: Proceedings of Third International Symposium Neotyphodium/Grass Interactions. Eds. Bacon, C.W.; Hill, N.S., Plenium Press, New York.

Solomons, R.N.; Oliver, J.W.; Linnabary, R.D. 1989. Reactivity of the dorsal pedal vein of cattle to selected alkaloids associated with Acremonium coenophialum-infected grass. American Journal of Veterinary Research 50: 235-238. 